\title{
CHARACTERIZATION OF POMEGRANATE CULTIVARS IN PALM GROVES OF THE OUED RIGH VALLEY (SOUTH-EASTERN ALGERIA)
}

\author{
A. ALLAM $^{1, *}$, M. TAMA ${ }^{1}$ \\ *E-mail: allam_aek@yahoo.fr, tama.mohamed2011@gmail.com
}

Received: Apr. 14, 2020. Revised: May, 18, 2020. Accepted: May, 23, 2020. Published online: June 5, 2020

ABSTRACT. Varietal recognition is a key step for good management of genetic diversity. Indeed, the morphological description of certain organs, such as the leaves, flowers, fruits and seeds, allow a more or less rapid and reliable identification of the varieties or cultivars. The culture of the pomegranate tree is very known in the valley of Oued Righ in the Algerian Southern, and it constitutes the main fruit species with a number of trees of $27.77 \%$ of total number. The pomegranate tree is found in more than $84 \%$ of the farms of the region and its production is complementary of that of the dates. Unfortunately, no study has been realized on the characterization and the valorization of this species. To know and identify the varieties or the existing cultivars, we have undertaken a work of characterization of clones cultivated in the valley of Oued Righ. The plant material constituted by 13 clones of pomegranate tree stemming from various farms. The method of work consists in taking 20 fruits by tree for physico-chemical analyses in the laboratory. The results of analyses on sample of 13 clones described five cultivars, among which some present acceptable characters of fruit from a caliber point of view, contents in sugars and acidity. It shows that the naming of cultivars by the farmers based only on the acid taste of fruits "Hamad" or sweetened "Hlou" is not scientific and remain insufficient. Our results confirm the usefulness of morphological descriptors in the characterization of plant genetic resources. However, more clarification can be achieved by the undeniable contribution of molecular markers.

Keywords: Oued Righ; Sahara; oasis; palm grove, cultivar.

\section{INTRODUCTION}

In Algeria, the problems of the of the agricultural sector and the needs of the population in fast demographic growth led to search the introduction of performance species and varieties, and marginalization of those local, which nevertheless better

\footnotetext{
${ }^{1}$ Experimental Station of Sidi Mehdi Touggourt, Algeria National Institute of Agronomic Research of Algeria
} 
adapted at the conditions of the soil and the climate. The agricultural development based on the intensification led to a double failure, that of the not control of the introduced varieties and the absence of preservation and valuation of the local varieties. The problem lives in the definitive loss of a part of our heritage, which remains still badly known, and which consequences are not at estimated presently.

The fruit cultivation is an integral part of the economic and social life of Algeria. This country due to its privileged geographical position and its diverse soil and climate conditions indeed has the possibility of putting in agriculture several fruit species and of producing fresh fruit all year round. In Algerian Sahara, the fruit cultivation is constituted by rustic species and characteristics of the region, as the vine, the olive tree, the citrus fruits, the palm tree date and by more demanding and delicate species, cultivated essentially in the fertile plains; they are the very important Rosaceae on the economic and social plan (Abdelguerfi and Ramdane, 2003).

Between palm trees date and fruit trees, the competition being situated at various levels: space, illumination, ground and water. Fruit trees can be in three types of situation: either in intercalary of the palm trees, or in underlying regular plantation, or in plot of land orchard inside stitches of palm trees. Besides, the production of fresh fruit is very complementary of that of the dates; it spreads out from the spring to autumn, for the oases of the North, and more or less all year round in those of the South (Ferry and Toutain, 1990).

In the Sahara, the fruit production remains insignificant, compared to needs, even if certain regions (M'zab and El Golea) produce oranges, lemons, apricots, pomegranates, figs, grapes, the marketed quantities are tiny and the main part is auto-consumed.

These farming are possible everywhere when the water of irrigation is not too much salted (less than $2 \mathrm{~g}$ to liters), but must be protected from the strong winds. In the majority of the cases, markets are fed by products that from the North coming (Dubost, 1986).

The valley of Oued Righ in the Algerian southern is characterized by a system of type oasis, which consists since Antiquity, in a vegetable association of three strata: that of the palm tree (and more particularly in the variety of date "Deglet Nour" intended for the export), that of the diverse fruit trees and that of the annual cultures. The favorable microclimate created by the date palm favors a food-producing mixed farming (truck farming, feeds, cereals) in association with a breeding, especially caprine, but also ovine of family type and in traditional conduct (Djenane, 1990). In this region, the fruit cultivation (the second stratum of agriculture) remained marginalized and practiced on a very small scale with some subjects of various species 
intended only for the family consumption. This system of production having traditionally for end a subsistence farming, knew a permanent backward movement and it is even endangered (Benziouche, 2006).

The cultivated fruit trees are diversified enough in the same farm (because of the objective of auto consumption). We find the tree fruits of pomegranate, apricot, vine, olive, pear, plum, citrus etc. It is about local populations, resulting from a long selection practiced empirically and preserved by the farmers. Although these populations cannot any more by themselves be on the base of profitable fruit cultivation; they represent a genetic heritage diversified and adapted to the local soil and climate conditions, which is advisable to know, to protect and to improve (Benziouche, 2006).

The culture of the pomegranate tree is very known in the valley of Oued Righ, it constitutes the main fruit species with a number of $27.77 \%$ tree, followed by the apricot tree and by the fig tree with, respectively, 18.59 and $17.42 \%$ and it is in more than $84 \%$ of the farms (Allam, 2015). Unfortunately, with the exception of the works of Allam and Cheloufi (2012) and Allam (2015) on its genetic diversity, no study was realized on this species. The characterization and the identification of this plant material turn out to be necessary as prerequisite to any program of preservation, improvement and varietal creation.
The present work returns from this perspective and suggests studying the physico-chemical characteristics of some local cultivars of pomegranate tree in southern Algerian.

\section{MATERIALS AND METHODS}

\section{Plant material}

The studies of the morphological variability concerned the fruit-bearing characters of thirteen cultivars of pomegranate tree stemming prospecting realized in the various palm groves of the valley of Oued Righ.

\section{Method of sampling}

According to Dagnelie (2003) and considering the heterogeneousness of the existing cultivars of pomegranate tree, we considered every tree as an experimental unity. The adopted method of sampling is the one of Alavoine et al. (1981), Watkins and Smith (2002) and Bellini et al. (1984). To do it, we chose five farms presenting a biodiversity of the fruit species. At the level of every farm, we took a tree by cultivar according to their availability and their local appointments by the farmers "Hlou" and "Hamad". For the taking of fruits, the applied method is the one of Mars and Marrakchi (2000) and Mars and Marrakchi (2004), consisting of setting a standard height (for example, the level of eyes) and to take 20 fruits by tree at the stage full maturation, distributed in diverse orientations, while avoiding those which are too much exposed outside of the foliage. The samples of taken fruits are taken to analyze them in the laboratory.

\section{Method of analysis}

For physico-chemical analyses of the fruits in the laboratory, we are based 


\section{VARIETAL DIVERSITY OF POMEGRANATE IN ALGERIAN OASES}

on the methods of Audigie et al. (1984), Amoros et al. (2000) and Mars and Marrakchi (2004). For that purpose, we took at random 15 fruits on which we study internal and external characteristics of the fruit, such as the external color of the fruit (CF), the color of the seed (CG), the weight of the fruit $(\mathrm{PF})$, the equatorial diameter of the fruit (DF), measured in the equatorial section, the number of sections of the fruit (NL), the length of the peduncle (Lpd) and the number of sepals (NS).

After having peeled fruits with hands, we take 25 seeds of every fruit, on which we make the following measures: the length of the seed (LoG), the maximal width of the seed $(\mathrm{LaG})$ and the weight of 25 seeds. Then, we take $100 \mathrm{~g}$ of seeds, by means of a mortar we extract the juice with which we make following measures: the total volume of juice of $100 \mathrm{~g}$ of seeds (VJ); the moisture content $(\% \quad \mathrm{H})$, determined by weighing before and after dehydration of $10 \mathrm{~g}$ of seeds to the steam at adjusted at $105^{\circ} \mathrm{C}$ until the obtaining of the constant weight; the content in dry matter (\% MS), determined by the formula: $\mathrm{MS} \%=100-\% \mathrm{H}$; the $\mathrm{pH}$ of juice; the total of the soluble solids (TSS), obtained with a refractometer and expressed in degrees of Brix scale; the acidity expressed in percentage of citric acid, estimated with the hydroxide of sodium $0.1 \mathrm{~N}$ and brought to $\mathrm{pH} 8.1$ (Girard, 1965). The contents in total reducing sugars (SRT) and initial reducing sugars (SRI) are determined according to method of Audigie et al. (1984).

\section{Statistical analyses}

A simple statistical analysis based on the averages of the results is used by means of the program XLSTAT (Version 2015.3.01.19097). The coefficients of correlation are calculated to show the links between the characters examined in this study. The data are then the object of an Analysis in Main Component (ACP) to classify, in a graphic form, the studied cultivars (Philippeau, 1986).

\section{RESULTS AND DISCUSSION}

The Table 1 shows significant differences between certain parameters, such as the weight of fruit (Pf) varies between 167 - $827 \mathrm{~g}$, the length of the peduncle (Lpd) 7.81 $27.55 \mathrm{~cm}$, the number of sections of the fruit (NL) 5 - 8, the weight of the seed (Pg) $6-9.5 \mathrm{~g}$, the volume of juice (VJ) 61 - $78 \mathrm{ml}$, the acidity 5.34 - 29.91, the total of the soluble solids (TSS), $10-20 \%$, the content in initial reducing sugars (SRI) 2.78 $7.73 \%$ and the content in total reducing sugars (SRT) of 3.26 $7.73 \%$.

On 16 studied parameters, six present minimal values for cultivars "Hamad" (Hm), they are: the diameter of fruit (Df: $7.16 \mathrm{~cm}$ ), the length of the seed (Log: $0.66 \mathrm{~cm}$ ), the $\mathrm{pH}: 2.89$; the total of the soluble solids (TSS: $10 \%)$, the content in initial reducing sugars (SRI: $2.78 \%$ ) and the content in sugars reducer totals (SRT: 3.26\%). While, the same parameters present maximal values for cultivars "Hlou" (Hl) are, respectively: $10 \mathrm{~cm}, 1.25 \mathrm{~cm}$, pH: 4.24, 20\%, 7.73\% and 7.73\%. 


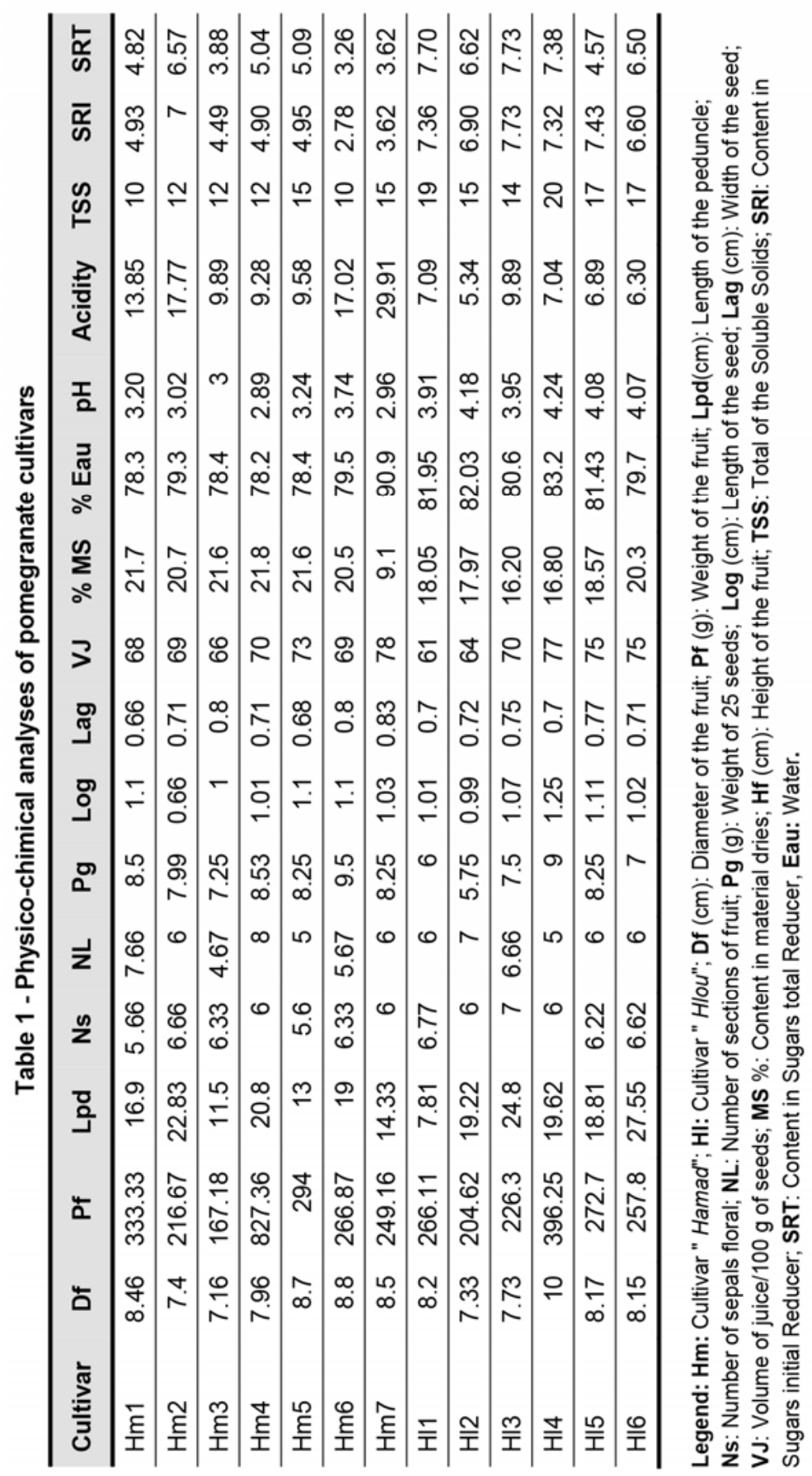


Cultivars "Hamad" (Hm) are characterized by an acid $\mathrm{pH}(2.96-$ $3.74)$ and high acidity $(9.28-29.91)$. On the other hand, these cultivars present a total of the soluble solids (TSS), a content in initial reducing sugars reducing (SRI) and a content in sugars total weak ones (SRT) are, respectively: $14-20 \%, 6.60-7.73 \%$ and $4.57-7.73 \%$.

Contrary to cultivars "Hamad", cultivars "Hlou" are characterized by a $\mathrm{pH}$ aiming towards an alkalinity (3.91 - 4.24) and a low acidity (5.34 9.89), a total of the soluble solids (TSS) a content in initial reducing sugars reducing (SRI) and a content in sugars high totals are, respectively: 10 $-15 \%, 2.78-7 \%$ and $3.88-6.57 \%$.

To observe better the variability inter cultivars, the analysis in main components (A.C.P) allowed us to make the results shown below.

\section{Matrix correlation}

The matrix of the correlations reveals several correlations between the various studied characters (Table 2). The positive correlations are observed between the following characters: the diameter of the fruit (Df), the weight of the seed (Pg) and the length of the seed (Log), that of fruits having seeds with high weights and high lengths have high diameters; a positive correlation between the weight of the seed (Pg) and the volume of juice (VJ); the fruits having fleshy seeds have a volume of high juice; a positive correlation between the $\mathrm{pH}$, the total of the soluble solids (TSS) and the content in initial reducing sugars (SRI); the more the rate of sugars increases the more the $\mathrm{pH}$ tends towards neutrality.

Thus, some parameters showed negative correlations, the most important in absolute value are recorded between: the content in dry matter (MS \%) and the moisture content ( $\mathrm{H} \%)$; the acidity and the content in initial reducing sugars (SRI); fruits having high content in sugars present a low acidity.

Table 2 - Matrix of the correlations of the pomegranate cultivars

\begin{tabular}{|c|c|c|c|c|c|c|c|c|c|}
\hline & Df & $\mathrm{Pg}$ & Lag & MS & Water & pH & Acidity & TSS & SRI \\
\hline $\mathrm{Pg}$ & 0.598 & & & & & & & & \\
\hline Log & 0.701 & & & & & & & & \\
\hline VJ & & 0.581 & & & & & & & \\
\hline Water & & & & -0.968 & & & & & \\
\hline Acidity & & & & & 0.565 & -0.590 & & & \\
\hline TSS & & & & & & 0.631 & & & \\
\hline SRI & & & & & & 0.610 & -0.605 & 0.628 & \\
\hline SRT & & & -0.564 & & & & & 0.571 & 0.864 \\
\hline
\end{tabular}

\section{Identification and classification of various cultivars}

The morphological and chemical data stemming from measures made on 16 characters of the fruit of the pomegranate tree were exploited. The obtained results show that both axes 1 and 2 contribute, respectively, to 


\section{A. ALLAM, M. TAMA}

$26.92 \%$ and $21.57 \%$ of the total inertia that is a percentage accumulated by $48.48 \%$ (Table 3 and Fig. 1). Consequently, we can say that the axis 1 contains the main part of the exploitable information.

On 16 characters of the fruit studied, eleven are discriminating, namely: the diameter of the fruit (Df), the weight of 25 seeds (Pg), the length of the seed (Log), the volume of juice (VJ), the content in dry matter (MS $\%)$, the moisture content (\% water), the $\mathrm{pH}$, the acidity, the total of the soluble solids (TSS), the content in sugar initial reducers (SRI) and the content in total reducing sugars (SRT).

Table 3 - Variable contributions (\%)

\begin{tabular}{lrr}
\hline & F1 & \multicolumn{1}{c}{ F2 } \\
\hline Df & 1,373 & 11,347 \\
\hline Pf & 0,461 & 1,582 \\
\hline Lpd & 1,299 & 0,024 \\
\hline $\mathrm{Ns}$ & 5,867 & 0,019 \\
\hline $\mathrm{NL}$ & 0,202 & 5,294 \\
\hline $\mathrm{Pg}$ & 10,636 & 0,151 \\
\hline Log & 0,328 & 8,434 \\
\hline Lag & 6,655 & 1,882 \\
\hline VJ & 3,946 & 10,303 \\
\hline$\%$ MS & 1,283 & 16,133 \\
\hline \% water & 2,312 & 16,032 \\
\hline pH & 9,583 & 8,514 \\
\hline Acidity & 14,464 & 0,226 \\
\hline TSS & 5,831 & 17,104 \\
\hline SRI & 18,041 & 1,751 \\
\hline SRT & 17,719 & 1,205 \\
\hline
\end{tabular}

The cloud of the individuals (Fig. 2) planned on the axis 1 and the axis 2 shows considerable differences between the various individuals. Indeed, the more the individuals are taken away from the center of the plan, the more they are dissimilar. But, if they are close to the center it indicates that they have common characteristics. According to the cloud of the individuals planned on the axis 1 and 2, a first classification of cultivars can be made. For that purpose, we can subdivide these trees into five cultivars.

Cultivar 1: this cultivar is positively localized with the axis F1 and the axis F2. It is constituted by the individual of pomegranate sweetened tree "Hlou" Hl4, characterized by the high values of the diameter of fruit (Df), of the length of the seed (Log), of the $\mathrm{pH}$ and by the total of the soluble solids (TSS).

Cultivar 2: this cultivar is localized positively with the axis F1 and negatively with the axis F2. It is constituted by the individual of acid pomegranate tree "Hamad" Hm7, characterized by high values of the width of the seed (Lag), the volume of juice (VJ), the moisture content (\% water) and of the acidity.

Cultivar 3: this cultivar is negatively localized with the axis F1 and the axis F2. It is constituted by the individual of acid pomegranate tree "Hamad" Hm6, characterized by a high weight of the seed (Pg), a low total of the soluble solids (TSS), a low content in initial reducing sugars reducing (SRI) and a low content in sugars totals (SRT).

Cultivar 4: this cultivar is negatively localized with the axis F1 and the axis F2. Itis constituted by the individual of acid pomegranate tree "Hamad" Hm4, characterized by a 
high weight of fruit (Pf), high number of sections of fruit (NL), a high content of dry matter (\% MS), a low moisture content (\% water) and a low $\mathrm{pH}$.

Cultivar 5: the cloud formed by this group is constituted by the individuals not discriminated from pomegranate acid tree "Hamad": Hm1, Hm2, Hm3, Hm5 and pomegranate Sweetened tree "Hlou": Hl1, Hl2, Hl3, Hl5, Hl6.

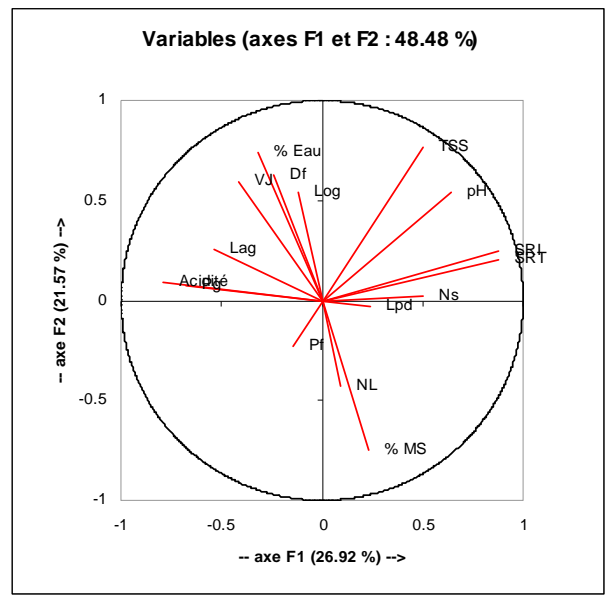

Figure 1- Circle of correlation of the various characters of the pomegranate cultivars
Surveys by Chouaki et al. (2006) on plant genetic resources have shown that there are many varieties of pomegranates of very different qualities. The most cultivated varieties in Oran region are: "Tendral" (called Molla), "Blanca", "Si Hueso", "Colorado". Thus, several kinds of pomegranate trees are reported in the Kabyle region, but we only know their local appellation (Lahlou, Elmouze).

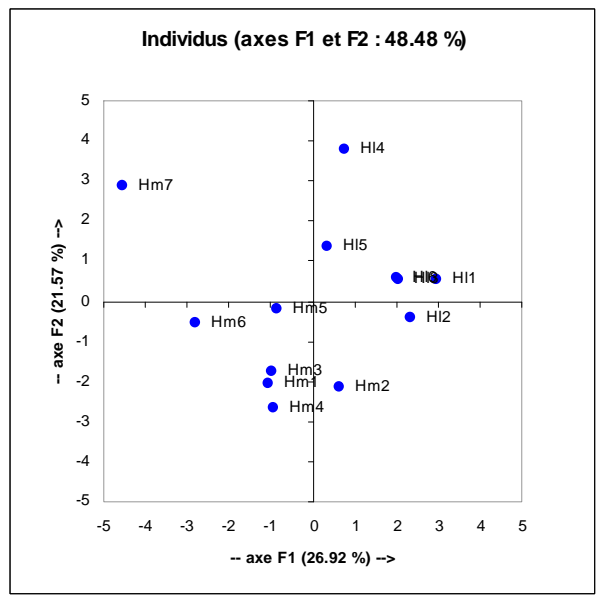

Figure 2 - Distribution of pomegranate cultivars by the ACP

Legend: Hm: Cultivar "Hamad"; HI: Cultivar "Hlou"

\section{CONCLUSION}

In all the region of study we noted no varietal naming of the pomegranate tree. The cultivated species form a set of cultivars selected by the farmers and named locally. To distinguish between the cultivars, the farmers based especially on the taste and sometimes on the outside color. For that purpose we registered only three naming of the pomegranate tree; they are cultivars "Hlou", which means sugar taste, "Hamad", which means acid taste and "Mouz", which means intermediate taste.

This problem of varietal misunderstanding of the local pomegranate tree does not lie only at the level of the region of study, but also at the level of other regions of the national territory, as in the Kabyle 
region, where the same names (Lahlou, Elmouze) are attributed by peasants. The physico-chemical characterization of 13 clones of pomegranate tree of the valley of Oued Righ allowed us to identify and to describe five cultivars, among which some present acceptable characters of fruit of seen calibre, contents in sugars and acidity. These cultivars deserve to be protected, improved and valued.

\section{REFERENCES}

Abdelguerfi, A. \& Ramdane, S.A. (2003). Evaluation des besoins en matière de renforcement des capacités nécessaires à la conservation et l'utilisation durable de la biodiversité importante pour l'agriculture. Bilans des expertises. FEM/PNUD. Projet ALG/97/G31. Plan d'Action et Stratégie Nationale sur la Biodiversité, Tome XI, $231 \mathrm{p}$.

Alavoine, F., Crochon, M., Fady, C., Fallot, J., Moras, P. \& Pech, J. (1981). $\mathrm{La}$ qualité gustative des fruits. Méthodes pratiques d'analyse. Méthode de présomption de la qualité gustative des pommes Golden délicious (indice de qualité) NFV 20 - 201. Edited by the French standardization association (AFNOR) Tour Europe Cédex 792080, Paris la Défense: 1-7.

Allam, A. (2015). Etude de la biodiversité des plantes cultivées des palmeraies de la région du Haut Oued Righ. Université de Kasdi Marbah Ouargla Algérie, Thesis. $125 \mathrm{p}$.

Allam, A. \& Cheloufi, H. (2012). Biodiversity of fruit species in the valley of Oued Righ: the case of the area of Touggourt (Algeria). Fruits, 68(1):1 -5, DOI: 10.1051/fruits/2012 048
Amorós, A., Melgarejo, P., Martínez, J.J., Hernández, F. \& Martínez, J. (2000). Characterization of the fruit of five pomegranate (Punica granatum L.) clones cultivated in homogeneous soils. CIHEAM Options Méditerr., Série A. Séminaires Méditerranéens, 42 :129 - 135.

Audigie, C.L., Figarella, J. \& Zonszain, F. (1984). Manipulations d'analyses biochimiques, Ed: Doin éditeurs. Paris, 88 - 97.

Bellini, E., Watkins, R. \& Pomarici, E. (1984). Peach descriptors. Apple descriptors. International Board For Plant Genetic Resources (IBPGR), Rome, Italy, $35 \mathrm{p}$.

Benziouche, S.E. (2006). L'agriculture dans la vallée de Oued Righ. Quelques éléments d'analyse. Université-Mohamed Khider, Biskra. Rev.Sci.Hum., 10: 19-34.

Chouaki, S., Bessedik, F., Chebouti, A., Maamri, F., Oumata, S., Kheldoun, S., Hamana, M.F., Douzene, M., Bellah, F. \& Kheldoun, A. (2006). Deuxième rapport national sur l'état des ressources phytogénétiques. INRAA, Algérie, $92 \mathrm{p}$.

Dagnelie, P. (2003). Principes d'expérimentation. Planification des expériences et analyse de leurs résultats. Les presses agronomiques de Gembloux, A.S.B.L. Belgique, $397 \mathrm{p}$.

Djennane, A. (1990). Les systèmes agricoles oasiens. Constat de situation des zones Sud des oasis algériennes. In: Dollé V. (ed.), Tou tain G. (ed.). Les systèmes agricoles oasiens. Montpellier: CIHEAM, 2940, Options Méditerran.: Série A. Séminaires Méditerranéens, 11: 2940.

Dubost, D. (1986). Nouvelles perspectives agricoles du Sahara algérien. Revue de l'Occident musulman et de la Méditerranée, 41-42: 339-356.

Ferry, M. \& Toutain, G. (1990). Concurrence et complémentarité des espèces végétales dans les oasis. In: Dollé V. (ed.), Toutain G. 


\section{VARIETAL DIVERSITY OF POMEGRANATE IN ALGERIAN OASES}

(ed.). Les systèmes agricoles oasiens. Montpellier: CIHEAM, 261270, Options Méditerranéennes : Série A. Séminaires Méditerranéens, 11: 19-21, Tozeur (Tunisia).

Girard, J. (1965). L'évolution de la datte au cours de sa croissance et de sa maturation. Compte rendu des travaux de recherches effectués à la station d'El-Arfiane, Algérie, $20 \mathrm{p}$.

Mars, M. \& Marrakchi, M. (2000). Variabilité intra-arbre chez le grenadier (Punica granatum L.): application à l'échantillonnage des fruits. Fruits, 55(5): 347-355.
Mars, M. \& Marrakchi, M. (2004). Analyse de la diversité génétique et sélection clonale chez le grenadier (Punica granatum L.). Revue des régions arides. Médenine, Tunisie, 1: 116-122.

Philippeau, G. (1986). Comment interpréter les résultats d'une analyse en composantes principales ? Institut Technique des Céréales et des Fourrages(ITCF), Paris, France, $61 \mathrm{p}$.

Watkins, R. \& Smith, R.A. (2002). Apple descriptors. International Board For Plant Genetic Resources (IBPGR). Rome, Italy, $49 \mathrm{p}$. 